\title{
Kitsch, crise da utopia modernista e crítica de arte na contemporaneidade
}

\author{
Arnaldo Franco Junior \\ Professor doutor em Letras, lotado no Departamento de \\ Estudos Linguísticos e Literários do Curso de Letras da \\ Unesp/São José do Rio Preto (SP).
}

Resumo: Análise das relações entre a crise dos paradigmas modernistas de criação e crítica de arte bem como da incorporação do kitsch pela arte a partir da segunda metade do século XX.

Palavras-chave: Modernidade; modernismo; kitsch; utopia; vanguarda
Abstract: In this paper, we analyzed the relationships between the crisis of Modernists paradigms of Art creation and criticism and the incorporation of kitsch by Art from the second half of the Twentieth Century.

Key words: Modernity; modernism; kitsch; utopia; vanguard 

A incorporação do kitsch pelas proposições estéticas pós-anos-50 do séc. XX foi uma evidência de que os paradigmas de crítica e de criação modernistas haviam entrado em crise, particularmente aqueles que articulavam a paixão crítica do artista moderno com a ideia de uma ação transformadora capaz de projetar, no presente, os signos e imagens de um futuro de liberdade, autonomia, realização individual, desalienação, desautomatização ou, noutros termos, a utopia moderno/modernista.

$\mathrm{O}$ vínculo entre crítica e criação sofre, nas manifestações estéticas pós-vanguardistas da segunda metade desse século, uma transformação evidente na assunção de uma posição autocrítica que acaba por limitar, em seu efeito de comentário, as ambições dos projetos e obras individuais ou coletivos. Tal deslocamento, metacrítico, opera uma relativização dos paradigmas e critérios de criação e de crítica modernistas. Segundo Philadelpho Menezes, esse traço é constitutivo da arte contemporânea produzida num contexto de metamodernidade ou modernidade autocrítica:

Enquanto a modernidade se marcou, em todas as suas manifestações, por colocar em crise e em crítica o passado frente ao advento de um presente imantado pelo futuro, no metamoderno abrese a crise desse futuro e a própria modernidade é muitas vezes tratada como o novo passado (MENEZES, 1994, p. 231).

As condições da arte e do artista no mundo da mercadoria e da sociedade de consumo passam a ser vistas, contemporaneamente, com menor euforia do que nos anos heroicos da afirmação das vanguardas modernistas; e, concomitantemente, os vínculos entre o processo de modernização e os projetos estéticos modernistas, particularmente visíveis no formalismo e no funcionalismo, passam, segundo Eduardo Subirats (1987), a ser vistos com suspeita e ironia. A utopia modernista, portanto, entra em crise, passando a ser vista como ideologia, ingenuidade e/ou, em certos casos, má fé1.
1 Para uma ideia dessa polêmica, consultar: Jürgen Habermas (1983); Jean François Lyotard (1983); Peter Bürger (1983). 
2 O conceito de indústria cultural foi definido por Adorno e Horkheimer em Dialética do esclarecimento, publicado em 1947.
A própria escolha de referências de mau gosto e do kitsch como material de criação foi o resultado de uma percepção do esgotamento da tradição modernista que animara a arte entre o final do século XIX e a primeira metade do século XX. Tal esgotamento faz-se notar, conforme demonstram Clement Greenberg (1954; 1979) e Umberto Eco (1970), tanto pela progressiva e cada vez mais célere neutralização, via apropriação publicitária, das proposições e resultados estéticos da vanguarda pela indústria cultural ${ }^{2}$ como, por outro lado, pela percepção de uma cada vez mais isolada atitude aristocrática incapaz de comunicar-se com o horizonte médio das experiências estéticas cotidianas na sociedade de massa. No artigo "As aporias da vanguarda", escrito nos anos 60, Hans Magnus Enzensberger afirma:

Igualmente como o comunismo na sociedade, a vanguarda quer estabelecer a liberdade nas artes de forma doutrinária. Dispõe da maneira mais precisa daquilo que é impreciso.

Dita arbitrariamente o que amanhã vai ter valor e ao mesmo tempo se sujeita, disciplinada e passivamente, aos ditados de um futuro que ela mesma decreta. Proclama que seu objetivo é a liberdade total e se abandona sem resistência ao processo histórico que tem que libertá-la precisamente dessa liberdade. (ENZENSBERGER, 1971, p. 101).

A incorporação do kitsch não foi a causa da crise da ideia moderna de arte de vanguarda nem da crise dos paradigmas de criação crítica do Modernismo; foi, antes, uma evidência do desgaste do projeto estético modernista e, também, em muitos casos, uma evidente tentativa de revitalizar a tradição da ruptura (PAZ, 1984) característica da Modernidade a partir da incorporação crítica de valores, signos e procedimentos marginalizados pelo purismo vanguardista. A produção estética pós-anos-50 do séc. XX evidencia tanto um desejo como um esforço de superação dos limites estabelecidos por suas antecessoras 
- objetivo visível na constatação de que a paixão crítica que caracterizara a arte de vanguarda expressava uma negatividade essencial à manutenção do equilíbrio dialético próprio da tradição moderna, acelerando-a, e reduzindo, de maneira drástica, o seu poder de fogo, o seu campo de atuação, a sua área de influência, a sua capacidade comunicativa e, mesmo, em certos casos, a sua própria pertinência.

A compreensão de tais esforços, movimentos e tentativas de ruptura com as limitações de um Modernismo academicizado passa, talvez, menos pela problemática e sempre polêmica escolha de um termo cuja substância conceitual demarque as diferenças entre a arte moderna e a arte neo-pós-metamoderna ${ }^{3}$ do que pela assunção, não menos problemática, de uma posição teleológica ou não teleológica no que se refere às concepções de tempo, história e cultura relativas ao mundo ocidental. Conforme João Adolfo Hansen (1994):

A recusa do tempo como desdobramento progressivo de uma Razão em direção à sua autorealização plena no futuro, como desenvolvimento de estágios em que se manifestaria uma necessidade ideal de transformações, do mais indeterminado ou "primitivo" para o mais determinado ou "civilizado", implica a crítica da representação e da teoria do discurso nela inserida. (HANSEN, 1994, p. 48).

A emergência, a partir dos anos 70, de um conjunto de reflexões contrárias à sedução das abstrações totalizantes e críticas em relação à herança do Projeto Iluminista, acabou produzindo um deslocamento dos paradigmas a partir dos quais a crítica cultural opera - no caso da crítica literária, por exemplo, é de notar um recrudescimento, dos anos 50-60 para cá e como efeito dos questionamentos efetuados em relação aos valores canônicos dos sistemas artístico e literário, das avaliações calcadas em critérios de gosto dados, antes, como absolutos. A investigação dos vínculos entre o poder, as abstrações metafísicas do Projeto

\section{Segundo João \\ Adolfo Hansen, "Uma cultura espetacular e narcísica recicla todos os tempos - 'neo' e 're' são os nomes do retorno do recalcado pela teleologia do 'anti' e não-teleologia do 'des' ” (HANSEN, 1994, p. 79).}


da Modernidade - Razão, Homem, Sentido da História, Progresso, Neutralidade Científica etc. - e a violência impuseram a metacriticidade, já presente no discurso das artes pós-anos-50, como procedimento comum também no discurso científico e no discurso da crítica. Tanto no debate Modernidade/-ismo versus Pós-Modernidade/ismo, que animou as últimas décadas do séc. $\mathrm{XX}$, como no embate entre intelectuais e teóricos herdeiros do Marxismo e intelectuais e teóricos críticos das heranças marxista e estruturalista e identificados com a contestação contracultural, pode-se encontrar uma evidência de que as posições em confronto não se restringem à ideologia, estendendo-se à base epistemológica que a ampara e da qual ela emerge.

O questionamento da existência de um sentido da história atesta tanto a forte presença de tal ideia, na verdade um dos fundamentos do Projeto da Modernidade, como o desgaste de seu vigor ideológico. Admitindo e professando a crença na existência de um sentido da história - regido necessariamente por um princípio racional que se manifestaria na sucessividade linear do tempo e seria reconhecido em conceitos como evolução, progresso, futuro etc. -, fica fácil definir o que é arte e o que é kitsch. No entanto, refutada ou seriamente abalada tal ideia, a questão se desloca da simples identificação de objetos ou da rígida substancialização das categorias de gosto, consciência e subjetividade para a avaliação crítica dos polos da enunciação e da recepção (pluralizada, heterogênea, multiforme) dos enunciados: Quem, afinal, define o que é ou não é arte/ kitsch? De que ponto de vista? Ligado a que conjunto de valores e a que ideário estético, político etc.?

O problema da construção social do imaginário passa a ser um dado importante nas discussões da crítica cultural contemporânea. Abalada a ideia de que a história tenha um sentido inerente, o imaginário social deixa de ser visto como algo fixo, uniforme, determinado a partir das injunções e influências exclusivas do meio, determinado exclusivamente pela posição de classe social 
etc. A ideia de que o imaginário social é um construto complexo e instável resultante do confronto de múltiplas categorias que interagem com a posição de classe social impôs a consideração da diferença aos discursos da ciência, das artes e da crítica cultural. Michel Foucault, por exemplo, demonstrou, em História da loucura (1978), a existência de vínculos entre a construção social do imaginário, a criação e a manutenção das instituições médico-psiquiátricas, a partir da institucionalização dos conceitos de doença mental e loucura, e o poder e a violência exercidos sobre as alteridades consideradas incompatíveis com a ordem dominante no mundo ocidental nas Idades Moderna e Contemporânea.

No que diz respeito ao kitsch, instala-se a necessidade de reconhecer o caráter de construto tanto do conceito como da metanarrativa (auto)legitimadora à qual ele se vincula, particularmente visíveis no discurso da crítica modernista vigente entre o final do século XIX e a primeira metade do século XX.

A vanguarda modernista não criou o conceito de kitsch, mas participou de sua criação e beneficiou-se dele para afirmar-se, valorizando as suas proposições e defendendo os seus valores estéticos, políticos, ideológicos, bem como a sua prática histórica. O kitsch foi definido particularmente pela crítica modernista comprometida com a defesa do Modernismo e da arte das vanguardas e, não raro, engajada, à direita e à esquerda, em projetos de transformação social. Foram poucos os artistas modernos que recorreram ao conceito de kitsch para definir e positivar, por oposição, a sua arte, as suas ideias e o seu projeto estético-político. No conjunto de manifestos das vanguardas modernistas é mais comum o uso de termos como "obsoleto", "passadista", "arte burguesa", "arte alienada", "bom gosto burguês" etc. do que a utilização do termo kitsch para estabelecer as oposições passado/ presente, antigo/moderno, alienado/crítico, entre outras.

A partir de um esforço de relativização da pletora utópica do Projeto da Modernidade e do Modernismo, foi considerada necessária a reavaliação tanto da definição 
como da utilização discursiva de conceitos como kitsch, sociedade de massa, cultura de massa, indústria cultural e estratificação cultural - o aparato que sustenta o discurso da crítica modernista na primeira metade do século XX. Num contexto de esgotamento e/ou academicização dos procedimentos do Modernismo e de reavaliação crítica da ideologia da Modernidade, o kitsch passa a ser visto como uma referência datada, um conceito circunscrito a um contexto sociocultural determinado que, embora não radicalmente superado, se encontra em crise e/ou se transformou consideravelmente.

Proceder à relativização do conceito de kitsch é uma forma de operar uma crítica às instituições que o criaram - a crítica modernista e a vanguarda -, valendo-se dele para instalarem-se como núcleos institucionais de poder-saber. Artistas e movimentos estéticos contemporâneos realizaram tal relativização desde que incorporaram o kitsch como matéria-prima e referência estético-ideológica em suasobras. Oconfronto entre proposições e projetos estéticos modernistas e neo-pós-metamodernistas não elimina a validade do conceito de kitsch nem do aparato conceitual a ele ligado no discurso da crítica cultural, mas contribui para uma reavaliação da rigidez das definições e da utilização de tais conceitos no que se refere à avaliação das manifestações estéticas contemporâneas.

Como pensar o kitsch num contexto de crise do Modernismo e/ou da Modernidade? - eis a questão que se coloca a partir dos anos 50 do séc. XX para artistas, intelectuais, críticos e outros. Um dos modos de responder a essa questão foi a análise e a avaliação de obras e de proposições estéticas que incorporaram o kitsch, tal como definido por uma ótica modernista, para desestabilizar tanto o conceito como a própria ótica a partir da qual ele fora formulado.

Com o deslocamento, na identificação do kitsch, da esfera da materialidade para a esfera da construção da leitura da obra de arte, dá-se, também, uma relativização que é, em si mesma, crítica em relação às proposições, por 
vezes dogmáticas, da crítica cultural modernista. Noutras palavras: passa-se a reconhecer que o problema é também da leitura a ser construída e não exclusivamente do objeto dessa leitura: a obra de arte. Isso não postula apenas a necessidade de uma formação do leitor da obra de arte por meio de instituições como a educação-objetivo intrínseco ao Projeto da Modernidade —, mas impõe, também, o reconhecimento de que um mesmo objeto pode vir a ser recortado e reconstruído, na leitura, por perspectivas, experiências e sensibilidades não necessariamente vinculadas às instituições educacionais e culturais oficiais, em geral identificadas com o modelo e com os valores da cultura erudita de extração europeia. Tal descentramento da leitura implica o reconhecimento de que a leitura autorizada pelas instituições oficiais de educação e cultura é apenas uma das muitas possibilidades de recorte, crítico inclusive, de leitura de um mesmo objeto. Critérios como a posição do sujeito da leitura, a sua (dele) inserção social ligada aos critérios de classe social, etnia, sexo/gênero e orientação sexual passaram a ser considerados vetores importantes na tarefa de relativização da imagem de lector universalis propugnada e defendida pelas práticas educacionais e culturais institucionalmente identificadas com os valores do Projeto da Modernidade.

O conceito de kitsch foi inegavelmente construído por um imaginário moderno que concebe o movimento da história como algo regido por um princípio racional capaz de, num eixo de sucessivas rupturas, estabelecer um contínuo progresso material e subjetivo humanos, fixando como ideal uma concepção de sujeito como algo que pressupõe a eliminação de toda e qualquer alienação ou aprisionamento a formas de sujeição histórica. O conceito de kitsch deve a sua existência a uma concepção teleológica de tempo e de história que entra em crise a partir da crítica à mi(s)tificação da vanguarda e, também, da razão instrumental que anima o Projeto da Modernidade. Não foi o espaço, mas o tempo que sobressaiu, sempre, na definição do kitsch e no reconhecimento de suas manifestações. Aliás, foi precisamente o conflito entre 
${ }^{4}$ É assim que o compreendem, por exemplo: Hermann Broch (1973a, 1973b), Adorno (1982), Clement Greenberg (1954; 1979), Dwight McDonald (1960), Abraham Moles (1975).

${ }^{5}$ A este respeito, consultar Barthes (1988) e Foucault (1992). diferentes concepções de tempo - manifestas em signos, procedimentos estéticos, comportamentos - aquilo que caracterizou a definição e a utilização do kitsch no discurso da crítica modernista e da arte de vanguarda. Criou-se, no discurso da crítica modernista, um eixo sintagmático em que, num momento anterior ao seu próprio modo de ver a arte, são colocados lado a lado o anacronismo, a alienação, o passadismo, a idealização e o sentimentalismo românticos, o irracionalismo, o mau gosto e o kitsch.

O kitsch foi definido como a contrapartida, em termos de reificação da consciência, da ideia de contemplação desinteressada e crítica da obra de arte e das dimensões estéticas da vida, inclusive aquelas da vida cotidiana ${ }^{4}$. É justamente a ideia kantiana de contemplação desinteressada e necessariamente distanciada da obra de arte que postula uma clara divisão racional entre o sujeito e o objeto da contemplação e da fruição estéticas, o que parece entrar em crise no contexto de crítica do Modernismo. Uma das evidências de tal crítica é a "morte" do conceito de obra, operada a partir dos anos 60-70 em diversos campos de manifestação artística (happenings, arte corporal, intervenções, performances, instalações); outra de tais evidências é a ideia da morte ou do apagamento do autor ${ }^{5}$, que passa a ser visto menos como um indivíduo do que como uma instância articulada por e articuladora de discursos heterogêneos.

Mantida a ideia da existência de um sentido teleológico da história - consubstancial ao discurso das vanguardas artístico-políticas modernistas - tornase fácil definir o kitsch como tudo aquilo que se opõe a ou não se enquadra na autonomia e na tradição do novo reivindicadas como traço ontológico pela arte moderna e suas representações institucionais. Entretanto, tal facilidade é passível de crítica, conforme demonstra Octavio Paz (1972):

A ideia da modernidade é filha do tempo retilíneo: o presente não repete o passado e cada instante é único, diferente e auto-suficiente. A estética 
da modernidade [...] não é idêntica à noção de progresso: é muito difícil - e mesmo grotesco afirmar que as artes progridem. Mas modernidade e progresso se parecem por serem manifestações da visão do tempo retilíneo. Hoje, esse tempo se acaba. Assistimos a um fenômeno duplo: crítica do progresso nos países progressistas ou desenvolvidos e, no campo da arte e da literatura, degeneração da "vanguarda". O que distingue a arte da modernidade da arte de outras épocas é a crítica - e a "vanguarda" cessou de ser crítica. Sua negação se neutraliza ao ingressar no circuito de produção e consumo da sociedade industrial, seja como objeto, seja como notícia (PAZ, 1972, p. 136).

Desvelado o sentido da história como uma ilusão, uma mi(s)tificação ideológica da razão instrumental onipresente na ordem capitalista e inerente ao projeto de modernização, dessacralizados o progresso e o futuro como, nas palavras de Octavio Paz (1984), ópio da religião iluminista que constitui o Projeto da Modernidade, fica mais difícil definir o kitsch. Ele permanece, em muitas obras e projetos estéticos neopós-metamodernistas como referência, mas avaliado, muitas vezes, como um fantasma e, em muitos casos, como sinédoque cuja função, na estratégia alegórica com que jogaram muitos artistas, é crítica em relação à vanguarda e à crítica modernistas. Fantasma do projeto estético e das pretensões político-ideológicas emancipatórias do Modernismo e da Modernidade, fantasma do vanguardismo, contrafação que denuncia a condição de mercadoria da arte moderna, academicizada pela incorporação de seus valores, práticas e proposições tanto pelas instituições oficiais de educação e cultura como, principalmente, pelo mercado, pois o que se operou, muitas vezes, pela assunção de estilemas, procedimentos e referências kitsch foi uma crítica à pretensão de autonomia inerente ao discurso da vanguarda e da crítica com ela comprometida. 
No contexto marcado pela indústria cultural e pelo hiperdesenvolvimento dos media - que, hoje, pode ser vista como uma segunda natureza que reivindica, dada a sua ubiquidade, a condição de primeira natureza no que se refere à construção da subjetividade, do imaginário e da experiência humana cotidiana - tornou-se difícil falar em kitsch nos termos da crítica modernista.

O kitsch, tal como observa a própria crítica modernista, é proteiforme, logo, não pode pressupor uma substância fixa sempre idêntica a si mesma ao longo do tempo. Sua identificação é, talvez, mais propriamente uma questão de pragmática do que de semântica, ou seja, implica necessariamente a relação com os polos da enunciação e da recepção do enunciado - define-se, pois, para aquele que assim o concebe/recebe ou está apto a fazê-lo a partir de certas condições e circunstâncias. É por isso que esforços como os de Abraham Moles (1975), embora importantes para uma descrição-caracterização dos princípios constitutivos das obras em que o kitsch se manifesta, revelam-se limitados e/ou passíveis de questionamento. A pressuposição da existência de uma "essência" do kitsch irmana-se, não raro, a uma concepção de leitura como algo restrito à imanência do objeto. E sabemos, hoje, que esta é uma visão limitada do problema da construção da leitura, da interpretação e da atribuição de valor, pelo leitor, aos textos e obras que lê. Concentrar o problema na esfera da abordagem imanentista é escamotear, em última análise, o problema político da construção e da formação do leitor num patamar de escolarização efetivamente democrático, plural e igualitário.

Tome-se, por exemplo, a definição das ideias de mau gosto e de alienação - duas das mais fortes constituintes do kitsch nos discursos da crítica e da vanguarda modernistas. Não há propriamente uma estrutura do mau gosto fundada numa substancialidade do kitsch e, embora no que se refere à ideia de consciência crítica a questão se coloque de maneira problemática, não há como sustentar o mesmo para o conceito de alienação. Umberto Eco (1970) tentou, não sem ironia, estabelecer uma estrutura 
do mau gosto; Abraham Moles (1975) definiu, com bom-humor mas sem ironia, um conjunto de princípios característicos do kitsch em suas manifestações a partir de uma abordagem crítica funcionalista do fenômeno. Mas tal conjunto de elementos de identificação, embora útil, tem o seu limite na vinculação aos valores do Projeto da Modernidade, aos vetores fundamentais da arte moderna e da reivindicação de uma radical autonomia no que diz respeito à arte - autonomia ligada tanto ao polo da produção como ao polo da recepção estética, já que, a partir de Kant, a contemplação desinteressada se erige em critério distintivo entre o que passa a ser estabelecido como gozo estético educado e o que passa a ser visto como hedonismo grosseiro no que se refere à recepção estética.

A incorporação do kitsch pela arte contemporânea torna difícil até mesmo a utilização do conceito, pois, uma vez incorporados funcional, orgânica e conceitualmente às obras, as referências e os materiais kitsch perturbam a pretendida distinção de fronteiras entre a arte e a antiarte, termo também utilizado para caracterizar o kitsch. A incorporação funcional elimina ou fragiliza a possibilidade de identificação do kitsch em termos semânticos, ou seja, barra a pretensão substancialista do imaginário moderno no que diz respeito às ideias de mau gosto, repetição, cópia e, mesmo, alienação. Deixa de ser possível, em muitas obras e projetos estéticos contemporâneos, identificar o kitsch como algo além de uma referência de função ambiguamente crítica tanto em relação ao universo de mau gosto e alienação evocados como em relação aos seus supostos antípodas representados pelos valores e procedimentos da arte moderna.

Dissemos anteriormente que o kitsché um conceito vinculado à concepção teleológica de tempo e história característica do contexto da Modernidade e perceptível no discurso das vanguardas e da crítica modernistas. Pois bem, num contexto de crise das concepções modernas de tempo e história, de cautela em relação à sedução das totalizações produzidas pelas metanarrativas que sustentam discursivamente o Projeto da Modernidade, 
o kitsch se torna uma referência temporal de natureza ambígua, ou seja, condensa, em muitas obras, tanto a referência irônica à reificação e à alienação da experiência humana sob a Modernidade como a referência, também irônica, ao desejo de autonomia e à pletora utópica do Modernismo. É nesse sentido que ele surge em boa parte das manifestações pós-vanguardistas a partir dos anos 50 do séc. $\mathrm{XX}$.

A utilização conceitual do kitsch com função crítica tanto no que se refere à sociedade e à cultura de massas como no que se refere à tradição aristocrática da arte da qual as vanguardas modernistas se tornaram herdeiras e mantenedoras dá-se a ver já na obra de artistas modernistas que, sem propriamente levantarem a bandeira da discussão teórica, discretamente questionaram valores e procedimentos fundamentais da herança modernista, avaliando-a criticamente em suas produções, saturando-a, colocando-a em crise. A obra de Marcel Duchamp é, disso, um exemplo emblemático.

Acirrada no contexto contemporâneo pós-anos 50, e tendo como um de seus marcos principais, no campo das artes plásticas, a Pop Art, a apropriação de signos, procedimentos, estruturas e gêneros considerados kitsch pela crítica modernista projeta, no horizonte da sociedade e da cultura ocidentais, uma crítica às utopias modernistas e, num espectro mais problemático e ambicioso, às bases do Projeto da Modernidade. Num contexto em que se torna evidente que os grandes ideais da Modernidade jamais se cumpriram senão numa escala restrita e, por uma série complexa de razões, exclusivista, uma tal incorporação do que é, numa visada moderna, kitsch impõe, no mínimo, uma dúvida sobre o alcance da utopia moderno/ modernista e de seus valores, uma desconfiança de que tal utopia poderia, ela também, revelar-se em sua função ideológica, como uma mi(s)tificação ética e estética. 


\section{Referências}

ADORNO, T. W.; HORKHEIMER, M. A indústria cultural: o esclarecimento como mistificação das massas. In: ADORNO, T. W.; HORKHEIMER, M. Dialética do esclarecimento. Trad. de Guido Antonio de Almeida. Rio de Janeiro: Zahar, 1985. p. 113-156.

BARTHES, R A morte do autor. In: BARTHES, R. O rumor da língua. Trad. de Mário Laranjeira. São Paulo: Brasiliense, 1988.

BROCH, H. Kitsch y arte de tendência. In: DORFLES, G. (Org.) et al. El kitsch - antología del mal gusto. Traducción Jaume Pomar. Barcelona: Lúmen, 1973a. p. 68-76.

BROCH, H. Notas sobre el problema del kitsch. In: DORFLES, G. (Org.) et al. El kitsch - antología del mal gusto.

Traducción Jaume Pomar. Barcelona: Lúmen, 1973b. p. 49-67.

BÜRGER, P. O significado da vanguarda para a estética contemporânea: resposta a Jürgen Habermas. Arte em Revista, São Paulo: Ceac, no 7, p. 91-92, ago. 1983.

DORFLES, G. Kitsch y Cultura. In: DORFLES, G. Nuevos ritos, nuevos mitos. Traducción A. Saderman. Barcelona: Lúmen, 1969. p. 181-201.

ECO, U. Apocalípticos e integrados. Trad. de Pérola de Carvalho. São Paulo: Perspectiva, 1970. p. 33-68.

ENZENSBERGER, H. M. As aporias da vanguarda. Revista Tempo Brasileiro, Rio de Janeiro: Tempo Brasileiro, oo 26-27, p. 85-112, jan./mar. 1971.

FOUCAULT, M. O que é um autor? Trad. de António Fernando Cascais e Edmundo Cordeiro. Lisboa: Vega, 1992.

FOUCAULT, M. História da loucura. Trad. de José Teixeira Coelho Netto. São Paulo: Perspectiva, 1978. 
GREENBERG, C. Vanguarda e kitsch. In: ROSEMBERG, Bernard; WHITE, David Manning. Cultura de massa. Trad. de Octavio Mendes Cajado. São Paulo: Cultrix, [198-]. p. 121-134.

GREENBERG, C. Vanguardia y kitsch. In: GREENBERG, C. Arte y cultura - ensayos críticos. Barcelona: Editorial Gustavo Gilli, 1979. p. 12-27.

GREENBERG, C. Crisi della nostra cultura. Aut-Aut - Rivista di Filosofia e di Cultura, Milano: Lampugnani Nigri Editore, no 19, p. 3-20, 1954.

HABERMAS, J. Modernidade versus pós-modernidade. Arte em Revista. São Paulo: Ceac, no 7, p. 86-91, ago. 1983.

HANSEN, J. A. Pós-moderno e cultura. In: CHALHUB, S. (Org.) et al. Pós-Moderno \&: semiótica, cultura, psicanálise, literatura, artes plásticas. Rio de Janeiro: Imago, 1994. p. 37-84.

LYOTARD, J-F. Resposta à questão: o que é o pós-moderno?. Arte em Revista. São Paulo: Ceac, no 7, p. 94-96, ago. 1983.

McDONALD, D. Masscult and midcult. Part 1. The Partisan Review. New York: Random House, no 2, p. 203-233, 1960.

McDONALD, D. Masscult and midcult. Part 2. The Partisan Review. New York: Random House, n. 4, p. 589-631, 1960.

MENEZES, P. A crise do passado - modernidade, vanguarda, metamodernidade. São Paulo: Experimento, 1994.

MOLES, A. O Kitsch - Arte da felicidade. Trad. de Sergio Micelli. 2 ed. São Paulo: Perspectiva, 1975.

PAZ, O. Os filhos do barro. Trad. de Olga Savary. Rio de Janeiro: Nova Fronteira, 1984.

PAZ, O. Invenção, subdesenvolvimento, modernidade. In: PAZ, O. Signos em rotação. Trad. de Sebastião Uchoa Leite. São Paulo: Perspectiva, 1972. p. 133-137.

SUBIRATS, E. Da vanguarda ao pós-moderno. 3 ed. São Paulo: Nobel, 1987. 